\title{
Relevance of environmental and public safety issues predicts public importance of economic vitality
}

\author{
R. Thomas, S. Conway, P. Washeba, R. Cameron \& R. Skidmore \\ Urban Environmental Research, LLC, USA
}

\begin{abstract}
The extant literature indicates that in times of economic hardship, people afford less attention to environmental issues and, intuitively, more importance to economic matters. One topic that is not provided in the literature is the relative individual importance of environmental issues; specifically, that more personally relevant issues may remain imperative in times of economic hardship. Additionally, persons may be more concerned about basic needs, such as public safety, compared to environmental issues. In this study, respondents were 600 adults during a recently documented recession. Participants indicated the most urgent environmental issue as water concerns. Due to the distress of water availability in the American southwest, the personally relevant environmental issue was conceptualized as water conservation. In order to maintain standardization of environmental issues across relevancy; another water related issue was chosen as the personally irrelevant environmental variable. Flood control, while vitally important due to urbanization, is not personally relevant. The other predictive variable, public safety; was measured as the importance of maintaining low crime rates. The prediction of the economic vitality variable was constructed as the importance of improving job opportunities, with higher importance of improvement indicating a poorer semblance of vitality. Data was analyzed using standard multiple regression and the results support the hypothesis. Specifically, in times of economic adversity, more importance is given toward public safety and personally relevant environmental issues, while less importance is focused on environmental issues that are personally irrelevant. The results and discussion are a pragmatic look into importance and perceptual influence on economic, public safety, and environmental issues.
\end{abstract}

Keywords: environmental issues, public safety, and economic vitality. 


\section{Introduction}

\section{Economic development}

The goal in economic development is to achieve and maintain economic welfare for individuals and sustain growth (Okina [13]). The conventional economic prosperity theory posits growth should be based on capital development, population increase, and advancements in technology instead of quantitative aspects such as monetary constructs. Some research shows, however, during times of crisis the way in which economies are valued is changed. Specifically, economies tend to be focused on more basic needs such as planning and preparation during instability (Perelman [14]). Further, some research suggests that as economies develop and augment, policies correspondingly adjust. This has been demonstrated as a concomitant increase in domestic environmental policies and economic expansion (Anderson [2]). That is, as an economy develops and grows, higher-level policies, such as environmental, garner more attention and amplification as well. Correspondingly, environmental issues are of higher importance in industrialized countries, which have basic needs met, as compared to developing nations who may worry about lower-level needs such as those for food, clothing, or shelter (Dunlap et al. [3]). One of the most influential theories in motivation and needs research proposed by Maslow [10-12] suggests a hierarchy of needs motivates persons. The needs in this hierarchy in ascending order consist of physiological, safety/security, social, ego/esteem, and selfactualization. According to the model, usually persons are required to fulfil lower order needs before progressing to higher order needs. That is, people will remain in their position until lower-level needs are met, at which point they will ascend the hierarchy. The highest order needs are associated with higher-level thought and meaning. Conversely, issues relating to basic needs are lower in the hierarchy and require less cognition. This research would suggest that at varying levels of economic development and prosperity, elements such as importance, focus, and attention correspondingly vary. One question posed by this variation in economic vitality and importance is, how does relative importance to persons affect these variables? One issue of limited investigation in the literature is the relative individual importance of environmental issues.

\section{Environmental concerns}

The existing literature indicates that in times of economic privation, people afford less attention to environmental issues and, intuitively, more importance to economic matters (Dunlap et al. [3]). Research suggests that while the United States is supportive of environmental issues as a nation, environmental concerns are not as salient as other issues and, therefore, are not considered as important. This suggests that issues have the potential to be placed on a continuum, thus creating varying levels of particular constructs (i.e. levels of relevance, importance, and salience will vary). Correspondingly, environmental issues have been referred to as "luxury" concerns because they are not of basic importance (Dunlap et al. [3]). That is, persons are less likely to support environmental initiatives during tough economic times on an individual level, and some 
research shows that there is a difference between importance of national economy and environmental issues, with the latter being less imperative (Lee and Norris [8]; Frazen and Meyer [5]). In order to ascertain the explanation between importance and issues, some research has investigated the difference in personal relevance in relation to environmental issues.

Research examining the personal relevance of environmental issues has found that in the majority of nations surveyed, environment has obtained a fair amount of concern (Dunlap et al. [3]). Environmental issues affect quality of life and environmental preservation is a key component to current political discussions (Kakrida [9]). Issues that affect quality of life are considered to be personally relevant because they directly affect the individual. The relative personal importance of environmental issues may influence the outcome and significance of the interactions of the variables. Specifically, environmental issues that are more personally relevant may remain important in times of economic hardship, while others that are less individually relevant would be less important. As evidence, environmental issues are of higher importance in industrialized countries, which have basic needs met, as compared to developing nations which may worry about food, clothing, or shelter (Dunlap et al. [3]). For those persons who may be concerned about basic needs, public safety, a very fundamental need, would plausibly be more important than environmental issues.

\section{Public safety concerns}

In addition to economic evaluation during times of basic need preoccupation, issues that are of public safety concern are considered to be more salient and important compared to environmental issues (Dunlap et al. [3]). Further, based on varying levels of economic stability cross-nationally, some nations will focus on more basic economic needs such as unemployment instead of higher-level concerns such as environmental issues (Lee and Norris [8]). Once more, it is posited that higher-level concerns are not concentrated upon until mandatory needs, such as safety, are met. Giving credence to this postulation, post materialistic values, which are considered to be higher-level, are associated with environmental concern (Lee and Norris [8]). Frazen and Meyer [5] discuss that environmental concern is associated with post materialistic values and persons with higher incomes in wealthier nations give more consideration toward environmental trends, issues, and concerns compared to those with lower sociodemographic variables.

Research has shown that public safety remains of high importance to persons regardless of economic conditions (UNLV Cannon Survey Center, Las Vegas Sun [17]. As demonstrated by Maslow [10-12], persons are required to fulfil low order needs before progressing to high order needs. The highest order needs are associated with higher-level cognition. Pertinent to the current investigation, topics relating to environmental issues require higher-levels of discernment. Conversely, issues relating to basic needs, such as those for safety, are lower in the hierarchy and require less cognition. During times of privation more basic needs are important over and above those that are non-essential. The basic need of public safety, i.e. maintaining low crime rates, would be considered more 
important than nonrelevant environmental issues, but as important as those distinguished as relevant.

\section{Hypotheses}

The current paper provides an empirical research investigation into the perception of economic vitality which was hypothesized to be predicted by the importance of a personally relevant environmental issue and a public safety issue. In addition, the importance of a personally irrelevant environmental issue was hypothesized not to predict economic vitality. Previous research on this topic provides correlation data corroborating the hypotheses, and the current study utilizes experimental research design.

\section{Methods}

\subsection{Participants}

Participants were 600 adults (296 males and 304 females) recruited from an online database of landline telephone numbers during a recently documented recession. Participation was voluntary and no monetary compensation was offered. The median age of the participants ranged from 25 to 44 with an overall range from 18 to 65 . The median income ranged from $\$ 40,000$ to $\$ 60,000$ USD.

\subsection{Procedures}

Participants were called and requested to answer questions regarding issues of importance to the residents of Southern Nevada in the United States of America. It was indicated that all responses would remain confidential and grouped for analysis. Upon agreement of participation, respondents answered questions regarding public safety, environmental, and economic issues. Subsequent to the completion of the survey, participants were thanked for their time and asked for demographic information including age and income.

\subsection{Measures}

To determine the relevant environmental issue, participants were asked to indicate the most urgent environmental issue affecting life, with the largest percentage stating water concerns $(45.7 \%)$. The subsequent most common responses were overpopulation $(16.3 \%)$, air quality $(15.3 \%)$, and energy use $(6.2 \%)$.

All measures, less the obtainment of water concern, were continuous variables with endpoints ranging from 1 (low) to 5 (high). Due to the distress of water availability in the American southwest, the personally relevant environmental issue was conceptualized as water conservation. Participants were asked "on a scale of one to five, where one means 'low importance' and five means 'high importance,' please rate the level of importance for water conservation. 
In order to maintain standardization of environmental issues across relevancy; another water related issue was chosen as the personally irrelevant environmental variable. Flood control, while vitally important in the American southwest due to urbanization, is not personally relevant. Participants were asked "on a scale of one to five, where one means 'low importance' and five means 'high importance,' please rate the level of importance for flood control.

The other predictive variable, public safety; was measured as the importance of maintaining low crime rates. Participants were asked "on a scale of one to five, where one means 'low importance' and five means 'high importance,' please rate the level of importance for maintaining low crime rates.

The prediction of the economic vitality variable was constructed as the importance of improving job opportunities, with higher importance of improvement indicating a poorer semblance of vitality. Participants were asked "on a scale of one to five, where one means 'low importance' and five means 'high importance,' please rate the level of importance for improving job opportunities.

\subsection{Summary}

Several independent variables were created in order to predict the outcome of the dependent variable. The predictive, or independent variables, in the current study were a public safety variable, measured via maintaining low crime rates; a personally relevant environmental issue variable, measured by water concern; and a personally irrelevant environmental issue variable, measured by flood control. The outcome, or dependent variable, was economic vitality, measured by improvement of jobs. All variables were analyzed via multiple regression analyses using a statistical software program.

\section{Results}

The survey had a margin of error of \pm 4 percent at the 95 percent confidence level. The data was collected for the purpose of the Clark County Monitoring Program (monitoringprogram.com). Data was analyzed using standard multiple regression analyses and the results support the hypothesis that economic vitality is predicted by personal relevance of the environmental issues and public safety. Specifically, in times of economic adversity, more importance is given toward public safety and personally relevant environmental issues such as water conservation, while less importance is focused on environmental issues that are less personally relevant such as flood control.

\subsection{Environmental issues}

Relevant environmental issue. Participants were asked "on a scale of one to five, where one means 'low importance' and five means 'high importance,' please rate the level of importance for water conservation $(\mathrm{M}=4.11, \mathrm{SD}=1.30)$. Results indicate the relevant environmental issue significantly predicts economic vitality (standardized beta $=.185, \mathrm{t}=4.65, \mathrm{p}<0001$ ). Specifically, as importance of 
economic vitality increases, so does the importance of the relevant environmental issue.

Irrelevant environmental issue. Participants were asked "on a scale of one to five, where one means 'low importance' and five means 'high importance,' please rate the level of importance for flood control $(\mathrm{M}=3.70, \mathrm{SD}=1.21)$. Results indicate flood control did not significantly predict economic vitality (standardized beta $=.045, \mathrm{t}=1.176, \mathrm{p}=.240$ ). Specifically, there was no relation between increases in importance of economic vitality and the irrelevant environmental issue.

\subsection{Public safety issue}

The other predictive variable, public safety; was measured as the importance of maintaining low crime rates. Participants were asked "on a scale of one to five, where one means 'low importance' and five means 'high importance,' please rate the level of importance for maintaining low crime rates $(\mathrm{M}=4.14, \mathrm{SD}=1.11)$. Results indicate public safety significantly predicts economic vitality ( standardized beta $=.319, \mathrm{t}=8.159, \mathrm{p}<.0001$ ).

\subsection{Overall model}

Data was analyzed using standard multiple regression analyses and the results support the hypothesis that economic vitality $(\mathrm{M}=3.92, \mathrm{SD}=1.30)$ is predicted by personal relevance of the environmental issues and public safety ( $\mathrm{R}$ square $=$ $.176, \mathrm{R}=.420)$. Specifically, in times of economic adversity, more importance is given toward public safety and personally relevant environmental issues such as water conservation, while less importance is focused on environmental issues that are not personally relevant such as flood control.

\section{Discussion}

It was hypothesized that a personally relevant environmental issue and a public safety issue would predict economic vitality during economic privation. In addition, it was predicted that a personally irrelevant environmental issue would not predict the economic variable. Results support the hypotheses. That is, an increase in importance of the personally relevant environmental issue was associated with an increase in importance of economic vitality; correspondingly there was no association with the irrelevant environmental issue and economic vitality. This study corroborates previous research and extends the scientific literature by addressing the hypotheses and theory through an empirical research design. One question posed by these findings is, why did type of environmental issue differ in predictive ability?

Importance of environmental issues is contingent upon relevance. Due to the higher-level cognitions involved with environmental processes, only those issues that are germane to the individual are considered important, particularly during times of economic deficiency. This research corresponds with past research 
indicating environmental issues are of higher importance in industrialized countries, which have basic needs met, as compared to developing nations which may worry about food, clothing, or comfort (Dunlap et al. [3]). Importance of environmental issue varied across relevance due to need motivation and satisfaction. Another reason for variability across issue may be due to another basic need; health in particular. Credence has been given to the assertion that environmental problems are health threats to persons, thus tapping into the lower-level need of safety and security (Dunlap et al. [3]). Some environmental issues may be seen as higher-level and "luxury" concerns, while others, such as health, may be seen as basic concerns and viewed as relevant across all levels of socioeconomic status and national wealth. Further, persons believe poor environmental issues will negatively impact the lives of future generations (Dunlap et al. [3]), thus creating the need for improvement for safety and health issues. One other reason relevance may vary across environmental issue is media promulgation. Personally irrelevant environmental issues may not be salient in the mind of persons because of media exposure. Public concern regarding the environment increases when societal attention is paid toward the specific issues, even if the issue is not worsening (Dunlap et al. [4]). Further, there has been an emphasis on social facets of environmental issues, and less attention paid to the actual physical consequences themselves.

It also was hypothesized that a public safety variable would predict economic vitality. This hypothesis was supported, being that an increase in importance of public safety was associated with an increase in importance of economic vitality. There are several possible reasons public safety predicted economic vitality. The results insinuate that base needs, such as those for safety, remain of high importance, regardless of economic condition (UNLV Cannon Survey Center, Las Vegas Sun [17]). The results of the current investigation correspond with previous research. Specifically, according to Maslow [11, 12], persons may not concentrate on higher-level needs until lower-level needs are met. One issue for future research would be person-dependent levels of basic needs. For example, one person may require a higher-levels of safety compared to another in order to meet the requirements to ascend to higher-level needs such as those for elevated cognition (Sassoon [16]).

Some research suggests the entire way in which economies are measured and evaluated should be reconsidered. For example, Abramovitz [1] posits economies should compare a country's Gross Domestic Product (GDP) to its total material requirement as a measure of economic sustainability. Environmental stability, and in turn economic sustainability, would be a basic requirement necessary for persons to be capable of higher-level cognition and concern, such as those for ancillary environmental issues. One area of research should examine personally relevant economic issues. A relevant economic issue could be conceptualized as job growth, while national Gross Domestic Product (GDP) would not. A person dependent economic variable may be minimum wage. This variable may be relevant for those of low socioeconomic status but not for their higher counterparts. In accordance with this demographic variable, affluence and socioeconomic status may also have an effect on the relevance of 
variables. For example, government assistance programs may not be apposite for those higher in socioeconomic status, but of direct relevance to those lower in the construct. Ryan and Deci [15] suggest that once certain levels of wealth have been obtained, the feelings of security and stability have been met. At this point, more wealth adds little to increase well-being. Instead, the attainment of higherlevel needs, such as psychological needs, should be more satisfying. Consistent with this reasoning Inglehart and Klingemann [7] found that happiness levels tend to be higher when average levels of income are high. Above a certain level of income however, happiness ceases to increase.

This study addressed one issue of methodological concern. Specifically, in past research participants have been asked about personal relevance directly, i.e. "How concerned are you personally about environmental problems?" (Dunlap et al. [3]). Participants were primed to think about the personally relevant issue, thus creating social desirability effects. Social desirability is a psychological mechanism used by persons in response to self-report items in which the respondent desires to be viewed in a positive light by others. Social desirability is an editing process by which persons think about potential responses to selfreport questions, and then answer in a manner that will make them look favorable. This process often leads to less accurate responses (Holtgraves [6]). Past research has demonstrated social desirability in psychological studies using self-report surveys (Holtgraves [6]). Participants may have wanted to be viewed positively in the eyes of the researchers, thus giving more credence to the importance of the environmental issues. The current study examined the social construct of relevance, without the confounding variable of social desirability. To determine the relevant environmental issue, participants were asked to indicate the most urgent environmental issue affecting life, with the largest percentage stating water concerns. Participants were not primed to think about personal relevance, instead to think about urgency.

Like all research studies, this design is not infallible and a couple of problems with the study in particular should be addressed. The sample may have biases, thus creating external validity and generalization issues. Specifically, the sample may be considered biased because of the population in Nevada. The sample was not randomized and, therefore, could be considered only externally valid to Nevada residents. The study, however, should be considered valid because the bias was overcome by using a valid sample size with appropriate confidence levels with corresponding confidence intervals. One other issue is the specific variables. In particular, water conservation would not be applicable to other areas of the globe such as the Pacific Northwest in the United States due to varying climatic environments. The overall theory is considered to be valid, however, because the constructs of personal relevance were addressed. The specific variables would need further investigation in future studies of varying environmental conditions.

Several implications may be drawn from the current study. To begin, previous research would indicate persons are no longer concerned about environmental issues due to the far more important concern of economic stability. In actuality, persons may remain concerned about environmental issues, but only those with 
direct or vital relevance. Law makers, government, and the private sector can use this information in deciding importance and priority of issues. Relevance to persons can be used as an important construct in the decision making process.

Future research should investigate other hierarchical needs within the context of the current research design. For example, it is plausible that economic instability would create an importance of other lower order needs such as physiological, be it food, water, or comfort; as compared to social needs such as those for affiliation.

\section{Conclusion}

The extant literature indicates that in times of economic hardship, people afford less attention to environmental issues and, intuitively, more importance to economic matters. Further, persons are less likely to support environmental initiatives during tough economic times on an individual level, and some research shows that there is a difference between importance of national economy and environmental issues, with the latter being less imperative (Franzen and Meyer [5]; Lee and Norris [8]). Environmental issues that are more personally relevant remain important in times of economic hardship, while others that are less individually relevant would be less important. In addition, persons may be more concerned about basic needs, such as those for public safety, compared to environmental issues. This would be particularly true for environmental issue containing less personal relevance. The current paper provided an empirical research investigation analyzing the relationship between perceptions of economic vitality in relation to environmental relevance and public safety.

\section{References}

[1] Abramovitz, J. N. Report turns 'economic-versus-environment' argument on its head. World Watch, 10(5), 9, 1997.

[2] Anderson, K. Economic Growth, Environmental Issues, and Trade. C.E.P.R. Discussion Paper, CEPR Discussion Papers: 830, 1993.

[3] Dunlap, R. E., Gallup, G. H., \& Gallup, A. M. Of Global Concern: Results of the Health of the Planet Survey. Handbook of Global Environmental Policy and Administration. Eds. D. L. Soden and B. S. Steel. Basel, Switzerland: Marcel Dekker, 1999.

[4] Dunlap, R. E., Lutzenhiser, L. A., \& Rosa, E. A. Understanding Environmental Problems: A Sociological Perspective. In Economy, Environment, and Technology: A socio-economic approach. Ed. B. Burgenmeier. Studies in Socio-Economics, N.Y: Sharpe, 1994.

[5] Franzen, A., \& Meyer, R. Environmental attitudes in cross-national perspective: A multilevel analysis of the ISSP 1993 and 2000. European Sociological Review, doi: 10.1093/esr/jcp018, 2009. 
[6] Holtgraves, T. Social desirability and self-reports: Testing models of socially desirable responding. Personality and Social Psychology Bulletin, 30, 161-172, 2004.

[7] Inglehart, R., \& Klingemann, H. Genes, culture, democracy, and happiness (pp. 165-183). In E. Diener and E. Suh, (Eds.) Culture and Subjective wellbeing. Cambridge, MA: The MIT Press, 2000.

[8] Lee, A, R., \& Norris, J. A. Attitudes toward environmental issues in east Europe. International Journal of Public Opinion Research, 12(4), 372-397, 2000.

[9] Kakrida, U. V. Strong links between the economy and the environment, Review of Economic Sciences, 12, 67-84, 2007.

[10] Maslow, A. H. Motivation and personality. New York: Harper \& Row Publishers, 1987.

[11] Maslow, A. H. The farther reaches of human nature. Oxford, England: Viking, 1971.

[12] Maslow, A. H. Toward a psychology of being. 2nd ed. Oxford, England: D. Van Nostrand, 1968.

[13] Okina, K. Concluding Panel Discussion: Sustained Economic Growth and Central Bankning: Introductory Remarks. Monetary and Economic Studies (Special Edition) 24, 217-224, 2004.

[14] Perelman, M. The perverse economy: The impact of markets on people and the environment. New York and Houndmills, UK: Palagrave Macmillan, 2003.

[15] Ryan, R. M., \& Deci, E. L. On happiness and human potentials: A review of research on hedonic and eudaimonic well-being. Annual Review of Psychology, 52, 141-166, 2001.

[16] Sassoon, J. Self-actualization: Theory and technology. Pointe Claire, PQ, Canada: Humanica Press, 262, 1988.

[17] UNLV Cannon Survey Center, Las Vegas Sun, 2009. 